\title{
Performance and Survival of Mutual Fund Mergers: Evidence from Frequent and Infrequent Acquirers
}

\author{
Narjess Boubakri $^{\mathrm{a}}$, Aymen Karoui ${ }^{\mathrm{b}}$, Maher Kooli ${ }^{\mathrm{c}}$
}

\begin{abstract}
In this paper, we study the determinants of mutual fund mergers, and the performance and survival outcomes of the acquirers involved in these mergers. Across all estimations, we distinguish between frequent and infrequent acquirer categories. We first find that the fund's performance, size, fees, flows and age guide the merger decision. Distinguishing between frequent and infrequent acquirers, we also show that, after the acquisition, the latter exhibit a larger decline in performance than the former. From deal to deal, frequent acquirers do not seem to target higher performing funds, and suffer from a worsening and persistently poor post-merger performance. We also find that the merger probability of the acquirer is negatively related to within-family acquisitions, mergers involving an infrequent acquirer, fund size and the performance of both the target and the acquirer. The target fund's size and performance have a more important effect on the survival of infrequent acquirers than on the survival of frequent acquirers.
\end{abstract}

Keywords: fund mergers, performance, frequent acquirer, infrequent acquirer, and survival JEL Classification: G11, G12, G14

\footnotetext{
${ }^{a}$ School of Business and Management, American University of Sharjah, Department of accounting and finance, NAB-110, P.O. Box 26666 Sharjah, UAE, Tel: (971) 6515 2587, Fax: (971) 6 5585065, Email: nboubakri@aus.edu

${ }^{\mathrm{b}}$ (Corresponding author) School of Management, Université du Québec à Montréal, Department of finance, 315 Rue Sainte-Catherine Est, Montréal, Québec, CANADA H2X 3X2, Tel : 514987 3000, 5067\#, Fax : 514987 0422, Email : karoui.aymen@uqam.ca

' School of Management, Université du Québec à Montréal, Department of finance, 315 Rue Sainte-Catherine Est, Montréal, Québec, CANADA H2X 3X2, Tel : 514987 3000, 2082\#, Fax : 514987 0422, Email: kooli.maher@uqam.ca.

We gratefully acknowledge financial support from the CDPQ Research Chair in Portfolio Management of the School of Management (UQAM).
} 


\section{INTRODUCTION}

Despite the development of competing investment vehicles such as insurance companies, exchange-traded funds and hedge funds, the mutual fund industry has continued to grow and become increasingly popular. As of the end of 2010, the US mutual fund industry had registered 8,545 individual funds, with \$11.8 trillion assets under management, involving about 44\% of US households. ${ }^{1}$ Along with these developments, the industry has witnessed a significant number of mergers and acquisitions (M\&As): during the 1965-2010 period, approximately one tenth of equity funds have been merged out of business, and half of all fund exits were due to acquisitions. Nonetheless, the mutual fund literature has paid little attention to the merger value creation process in comparison with the number of studies on fund performance (Elton, Gruber, and Blake, 1996; Carhart, 1997; Kothari and Warner, 2001) and persistence (Brown and Goetzmann, 1995; Malkiel, 1995). ${ }^{2}$ The purpose of this study is to fill this gap in the literature by examining the acquirer's and the target fund's performance as well as the survival of funds involved in mergers, using a sample of 2,040 US equity fund mergers during the 1965-2010 period, which covers several economic cycles.

In running our analysis, we distinguish between frequent and infrequent fund acquirers. We define frequent acquirers as funds involved in at least two acquisitions, while infrequent acquirers are those that have made only one acquisition. In accordance with the corporate M\&A literature, which shows that the number of deals proxies for the acquirer's overconfidence level (Doukas and Petmezas, 2007; Billett and Qian, 2008), we conjecture that frequent and infrequent acquirers may have different motives for pursuing acquisitions: for example, hubris behaviour, superior managerial skill, empire building, executive compensation, and the management

\footnotetext{
${ }^{1}$ See ICI fact book, 2011, pages 16, 22 and 78.

${ }^{2}$ See Smith (2009) for a comprehensive literature review on mutual fund performance.
} 
learning effect (Rosen, 2005; Croci and Petmezas, 2009; Aktas, De Bodt, and Roll, 2011). Thus, distinguishing between these two types of acquirers according to the number of deals they make could add to our understanding of managerial behaviour. Further motivating our study, we find in our sample that frequent acquirers account for $43.0 \%$ of the total number of deals and $47.2 \%$ of the deals' value over the 1965-2010 period.

Our study complements two previous articles that addressed the mutual fund merger issue: (1) Jayaraman, Khorana, and Nelling (2002) examine the effect of mutual fund mergers on the acquirer's and the target's performance and find that acquiring funds experience a significant deterioration in performance after the mergers. We go beyond this study by examining the determinants of the merger decision and the survival of the acquiring funds. (2) Zhao (2005) studies fund family motivation to terminate funds and compares the delisted funds' with the acquired funds' performance. While these two studies and that of Ding (2006) restrict the distinction to within and across either family or objective mergers, our empirical design draws attention to the differences between frequent and infrequent acquirers.

Our paper also contributes to several strands of literature: (i) By examining whether M\&As are value-generating or value-destroying transactions in the mutual fund industry, we add to the corporate M\&A literature that has previously documented positive (negative or insignificant) abnormal returns for target (acquiring) firms, respectively, following the deal announcement (Betton, Eckbo, and Thorburn, 2008). Existing evidence also shows that, after a merger, the performance of the acquiring firm is likely to decrease (Agrawal, Jaffe, and Mandelker, 1992; Fuller, Netter, and Stegemoller, 2002). ${ }^{3}$ We provide new evidence, not only on the value creation of M\&A transactions in the mutual fund industry, but also by looking at the determinants of the

\footnotetext{
${ }^{3}$ Martynova and Renneboog (2008) offer an expansive survey of papers on M\&As. DeYoung, Evanoff, and Molyneux (2009) offer a survey on financial institution mergers.
} 
survival of the acquirers. (ii) In addition, we focus on the consequences of investor overconfidence bias. The effects of this bias have been studied in various contexts: analyst forecasts (Friesen and Weller, 2006), bidding activity in initial public offerings (IPOs) (Hsu and Shiu, 2010), trading activity (Barber and Odean, 2002; Grinblatt and Keloharju, 2009) and corporate acquisition decisions (Doukas and Petmezas, 2007; Billett and Qian, 2008). We extend this literature by examining the effects of this bias on the mutual fund acquisition decision. (iii) Finally, we contribute to an emerging literature on fund survival issues. While performance and flows are strongly negatively related to fund exit chances (Lunde, Timmermann, and Blake, 1999; Horst, Nijman, and Verbeek, 2001; Zhao, 2005; Massa and Patgiri, 2009), our paper distinguishes itself by investigating the impact of the acquisition on the acquirer's survival.

By way of preview, our empirical results indicate the following: First, we show that for the acquiring fund the likelihood of an acquisition is higher if it has poor past performance and is of a younger age. The probability of being acquired is, on the other hand, higher when the target fund has poor past performance, a smaller size and low flows. When we distinguish between the mergers completed by frequent and infrequent acquirers, we find that frequent acquirers engage in takeovers regardless of their own past performance and size, while infrequent acquirers are more likely to initiate takeovers if they are smaller, and when they are exhibiting negative performance. Both frequent and infrequent acquirers target small and poorly managed funds. Second, when we compare the performances of the acquiring funds before and after the acquisitions, we find, for the entire sample and in line with the literature (Jayaraman, Khorana, and Nelling, 2002; Allen and Parwada, 2006; Ding, 2006), a decrease in the acquiring fund's performance following the acquisition. We also observe that infrequent acquirers exhibit a greater decrease in performance than frequent acquirers, and that both frequent and infrequent 
acquirers select target funds that are performing more poorly than they are. The difference in performance between the acquirer and the target is larger for frequent acquirers. From deal to deal, frequent acquirers do not significantly change their target choice criteria, but they suffer from a deteriorating and persistently poor post-merger performance pattern. Finally, the third set of results, which relates to the study of the impact of the acquisition on the acquiring fund's survival in the years following the merger (using logit and Cox models), shows that poor performance, youth, and low flows on the part of the acquirer positively affect the likelihood that it will be merged out subsequent to the merger. Similarly, poorly performing and small-sized targets decrease the acquiring fund's survival likelihood. In addition, we find that within-family and frequent-acquirer acquisitions increase the survival rate, whereas the target's size and performance are more important factors in the merger probabilities of infrequent acquirers than of frequent acquirers.

The remainder of the paper is organized as follows: Section 2 summarizes the mutual fund M\&A literature findings and Section 3 describes our sample. Section 4 presents the methodology and empirical results. Section 5 concludes.

\section{M\&As IN THE MUTUAL FUNDS INDUSTRY: LITERATURE REVIEW}

The seminal paper of Jayaraman, Khorana, and Nelling (2002) examines pre- and postmerger fund performance. The authors find a decrease in the acquirer's performance around the merger and show that the acquirers perform relatively better than their targets do. Focusing on post-merger performance, Ding (2006) analyses the determinants and consequences of mutual fund mergers using a large sample of US mutual funds, and provides evidence of performance deterioration subsequent to the mergers. Adopting another perspective, Zhao (2005) studies the determinants of fund exits. The author categorizes the exits into liquidations and mergers, and 
finds that the probability of being acquired by a fund in the same family is positively related to the family size and the number of share classes offered. More recently, in addition to analysing the target shareholders' wealth in across-family mergers, Khorana, Tufano, and Wedge (2007) examine the impact of the merger event on the board of the acquired fund. The authors find that mergers benefit target shareholders at the expense of board members and are more likely to occur when the target's performance is poor. They also sustain that (at least in across-family mergers) trustees put the interests of the shareholders before their own. In a theoretical economic model, Park (2008) distinguishes funds based on the manager's incentives to merge. Consistent with the theoretical model predictions, she empirically finds that funds with low managerial incentives are not only more inclined to acquire, but are also more likely to achieve a lower performance. Using stochastic discount factor-based measures, Gargouri and Kryzanowski (2011) examine the post-merger risk-return profile of the acquiring funds in 6,680 mergers over the period 1962-2009. They find that risky portfolios become less efficient in the post-merger period, while the bidder's return and the target's risk respectively positively and negatively affect the probability of success of the merger. Allen and Parwada's (2006) study is the only one dedicated to non-US fund mergers. The authors analyse the effects of mergers on fund flows within an Australian mutual fund sample and show that the merger event causes the overall inflows to the fund to deteriorate. Subsequent to mergers, specialist funds exhibit an increase in total net assets, while the fund fee declines in the money market category.

Our study seeks to contribute to the existing evidence reviewed above by investigating several aspects related to M\&As conducted by serial and infrequent fund acquirers. This distinction is a novel aspect of our paper and leads us to explore the learning process, the persistence of acquirer performance and the selection of potential targets across both categories 
of acquirers. We also examine whether being a frequent acquirer enhances the probability of survival in the long run. Our analysis and results bridge the M\&A finance and mutual funds literatures, where the distinction between frequent and infrequent acquirers has not been documented to date.

\section{DATA}

\subsection{Sample selection}

We retrieve information about mutual funds, from January 1965 to December 2010, from the CRSP mutual fund database. The final sample consists of 3,566 funds, involving 2,040 acquisitions and 1,516 acquirers. These numbers yield an average of 1.34 deals per acquirer. Among the 2,040 mergers, 959 are within-family and 1,081 across families. We select US equity funds based on the self-declared styles provided by the Wiesenberger and Lipper classifications. We also extract the monthly net returns, the monthly total net assets (TNA), the annual fund fees and the turnover as well as the CUSIP of the acquirer, the date of the acquisition, and information as to whether a fund was liquidated or merged with another fund. For the purpose of our study, we select only merged funds (i.e. the variable 'delist_cd' in the CRSP fund database must indicate the value ' $M$ '). To ensure that the reported acquisition dates are consistent, we compare the reported fund returns with the merger date file. We obtain a correspondence between the merger and monthly returns files in 1,816 out of 2,040 merger dates. In cases of mismatch we manually cross-check this information on the internet. ${ }^{4}$ If this information is not available — mainly for mergers in our sample that occurred before the 1990s—we rely solely on the returns file information. Also, although, prior to the 1990s, the merger date is reported as the

\footnotetext{
${ }^{4}$ For the 224 mismatch cases, the average difference between the reported fund returns and the merger date files is 242.72 days (54.46 days when excluding the pre-1990 period). Since most of our tests rely on yearly frequency data or intervals of more than 12 months, this date discrepancy has a marginal effect on our results.
} 
year-end, we choose to include these funds even though we may miss out on some of the monthly precision. ${ }^{5}$ We follow Jayaraman, Khorana, and Nelling (2002) and include share class mergers in the mutual fund sample. ${ }^{6}$

\subsection{Descriptive statistics}

Panel A of Table 1 presents the TNA of the target funds and total equity funds for a number of periods. The third and fourth columns show the ratio of the target's TNA to the equity fund industry TNA and the number of mergers, respectively. The value and number of mergers clearly follow upward trends, more noticeable in the 2001-2010 period. However, when compared to the total equity funds' TNA, the value of the deals remains relatively stable in the last two decades.

Panel B of Table 1 displays the frequency distributions of the numbers of acquisitions made by each acquirer and their corresponding TNAs. About one quarter (23.4\%) of all sampled funds made more than one acquisition, with a maximum of nine, and 76.6\% made only one acquisition, over the sample period. Relative to the industry TNA, the funds that made only one acquisition account for $52.8 \%$, while those that made between two and nine acquisitions account for $47.2 \%$ of the total industry TNA. These numbers suggest that, although those funds that acquire more frequently account for only one quarter of all funds, the sizes (TNA) of their targets relative to the whole industry nonetheless make them as important as the infrequent acquirers. This is confirmed in Panel C of Table 1, where we examine more closely the summary statistics of the frequent and infrequent acquirers in terms of the number and size of deals made. While frequent acquirers represent just $23.4 \%(1,162)$ of the acquiring funds $(1,516)$, they account for $43.0 \%$ of the number of deals made (and $47.2 \%$ of their total value as mentioned above).

\footnotetext{
${ }^{5}$ Our results remain very similar when we exclude the 1965-1988 period, which accounts for only 279 of the mergers (i.e. $13.68 \%$ of our sample).

${ }^{6}$ Our results remain unchanged if we consider unique share class funds for the merger event.
} 
Panel A of Table 2 displays the frequency distribution along two dimensions: frequent or infrequent acquirers, and within- or across-family mergers. Within-family (across-family) mergers represent $47 \%$ (53\%) of the total number of transactions. The results show that these two distinctions (frequent versus infrequent and within versus across-family) do not overlap. For instance, frequent acquirers account for $31.90 \%$ (close to a third) of within-family acquisitions, but represent 52.91\% (half) of across-family acquisitions. Panel B of Table 2 reports the top ten merger transactions (in terms of target value) in our sample: we note that frequent acquirers and across-family mergers dominate the large deals.

\section{****Insert Table 2 about here****}

Figure 1 reports the number and value of mergers each year from 1965 to 2010, highlighting four merger waves corresponding to 1972-1978, 1985-1992, 1995-2001 and 2002-2007. Though our sample is restricted to equity open funds, the last three wave intervals match the merger waves observed at the corporate level (Gaughan, 2011, page 35). This suggests that mergers in the mutual fund industry could be affected by the same factors as the corporate M\&A market. 


\section{METHODOLOGY AND EMPIRICAL RESULTS}

\subsection{The determinants of mutual fund mergers}

\subsubsection{The merger decision}

In a fund merger the acquiring fund pursues external growth by acquiring another fund (i.e., the target), which then ceases to exist. Hence, unlike corporate firms, mutual funds do not conduct partial mergers. Furthermore, in a fund merger, the acquired fund's shares are transferred at their net asset value, while in a corporate merger the target stock price is usually determined through a bidding process or a negotiation between the acquirer and the target. Consequently, we study the performance of the acquiring fund for both the pre- and post-merger periods, while the study of the target fund is restricted to the pre-merger period. The date of the deal announcement is not available in our dataset but is unlikely to have the major effect it has in the case of listed firms. For our purposes, therefore, we use the effective date of the merger.

Evidence in the corporate M\&A literature shows that synergy, growth and diversification are the main motivations for entering into a merger process (Jensen, 1988). In the mutual fund industry, Jayaraman, Khorana, and Nelling (2002) assert that poor performance, insufficient inflows and an aspiration to benefit from economies of scales are important motivations to merge. While the latter authors limit their analysis of the determinants of a merger to the target's side, Ding (2006) examines the determinants of an acquisition from the acquirer's perspective. In our analysis, we examine the determinants of the acquisition decision at the fund level. Specifically, we use the following logistic regression model for each acquirer and for each target fund to assess the acquisition decision of the acquirer and the target fund's probability of being acquired and run the regression separately for all acquirers and all targets: 


$$
\begin{aligned}
\text { Merger Dummy }_{i, t} & =a_{1}+a_{2} \text { Alpha }_{i, t-1}+a_{3} \ln \left(\text { TNA }_{i, t-1}\right)+a_{4} \text { Turnover }_{i, t-1}+a_{5} \text { Fees }_{i, t-1} \\
& +a_{6} \text { Age }_{i, t-1}+a_{7} \text { Flows }_{i, t-1}+\varepsilon_{i, t}
\end{aligned}
$$

where Merger Dummy is a binary variable equal to 1 if the fund engages in a merger event in year $t$ and 0 otherwise; Alpha is the Carhart (1997) risk-adjusted performance of the fund 12, 24 or 36 months before the merger date; $\ln (T N A)$ is the natural logarithm of the total net assets (TNA); Turnover is expressed as a percentage and proxies for the rebalancing activity of the fund portfolio; Fees are the fund loads; Age is time since the fund inception, calculated in months; $\varepsilon$ is the unexplained component of the number of mergers, and Flows are measured as a percentage using the following formula:

Flows $_{t}=\frac{\text { TNA }_{t}-\operatorname{TNA}_{t-1}\left(1+R_{t}\right)}{T N A_{t-1}} \times 100$

where $T N A_{t}$ and $T N A_{t-1}$ are total net assets in year $t$ and $t-1$, respectively, and $R_{t}$ is the fund return in year $t$. All of the variables used in Equation (1) apply to either the acquirer or the target fund in question. The logistic regression is run using yearly frequency data and is clustered along two dimensions, funds and years, to control for time and firm effects respectively (Petersen, 2009; Thompson, 2011).

Table 3 reports two panels: In Panel A, we explore the merger decision based on the acquirer's characteristics, while in Panel B, we control for the target characteristics. In columns (1), (3) and (5), we only control for the performance of the funds calculated over 12, 24 and 36 months respectively. The performance of the acquirer loads negatively in all three models, and is significant for the 24- and 36-month calculations at $10 \%$. When we add the acquirer's control variables, shown in columns (2), (4) and (6) of Panel A, we find that the merger decision is systematically and negatively related to the acquirer's performance and age, suggesting that 
poorly performing acquirers that are relatively younger are more likely to engage in acquisitions. On the other hand, looking at Panel B, we find that the poor performance (calculated over different horizons) of the target has a negative effect and is highly significant (at the $1 \%$ level) in the baseline regression reported in columns (1), (3) and (5). After we control for the target characteristics, we find that smaller funds, those that exhibit poor performance and those with low inflows have a higher probability of being acquired. The negative coefficients of performance, size and flows are in line with the results of Jayaraman, Khorana, and Nelling (2002) and Zhao (2005).

**** Insert Table 3 about here****

\subsubsection{Frequent versus infrequent acquirer mergers}

The corporate finance literature asserts that managers could be subject to overconfidence bias (Doukas and Petmezas, 2007; Billett and Qian, 2008; Aktas, De Bodt, and Roll, 2011). This bias is likely to upwardly influence their bidding activity in IPOs (Doukas and Petmezas, 2007), trading (Barber and Odean, 2002), corporate investment distortion (Malmendier and Tate, 2005) and acquisition propensity (Lin et al., 2008; Aktas, De Bodt, and Roll, 2011; Dutta, MacAulay, and Saadi, 2011). Especially of interest to our analysis, Doukas and Petmezas (2007) and Billett and Qian (2008) argue that overconfidence bias induces an increase in the corporate acquisition frequency. Mutual fund managers are not exempt from the overconfidence bias seen among corporate managers. To assess the heterogeneity induced by such a bias, we examine the differences in characteristics between two groups of funds: frequent and infrequent acquirers, the former being more likely to exhibit overconfidence.

Our goal is to understand the various conditions under which a target is more likely to be acquired by a frequent than an infrequent acquirer. To do so, we link the type of acquirer to its 
own and its target's characteristics, and run the following multinomial logistic regression model for the acquisition of a particular target fund by a particular acquiring fund:

$$
\begin{aligned}
{\text { Frequent } \text { Merger }_{i, t}} & =a_{1}+a_{2} \text { Alpha }_{i, t-1}+a_{3} \ln \left(\text { TNA }_{i, t-1}\right)+a_{4} \text { Turnover }_{i, t-1}+a_{5} \text { Fees }_{i, t-1} \\
& +a_{6} \text { Age }_{i, t-1}+a_{7} \text { Flows }_{i, t-1}+\varepsilon_{i, t}
\end{aligned}
$$

where Frequent Merger is a categorical variable that equals 0 if the fund is not involved in a merger, 1 if the merger involves a frequent acquirer and 2 if it involves an infrequent acquirer. The other variables are defined as in Equation (1). The multinomial logistic regression is clustered at the fund level to control for time effects and we add dummy year variables to control for firm effects (Petersen, 2009; Thompson, 2011) and is run separately for all acquirers and all targets. ${ }^{7}$

Panel A of Table 4 shows that the frequent acquirers have insignificant performance (Alpha) coefficients irrespective of the horizon of the performance calculation, while the infrequent acquirers display negative coefficients for all horizons: Alpha loads negatively and significantly at the $10 \%$ level. This result is consistent with takeovers being strategically driven among frequent acquirers, who seem to engage in takeovers regardless of their own performance. In contrast, infrequent acquirers are more likely to resort to acquisitions only when they have registered a poor performance. The same holds true for the acquirer size (measured by TNA) as the variable is an insignificant determinant of the merger decision for frequent (as opposed to infrequent) acquirers. Larger fees incentivize (discourage) frequent (infrequent) acquirers to engage in merger transactions, but Age is negatively related to the merger decision for both types of acquirers. Finally, a higher turnover is significantly and positively related to the acquisition

\footnotetext{
${ }^{7}$ We define frequent acquirers as funds that make more than one acquisition over the sample period. We are aware that in doing so, we could introduce a 'look-ahead' bias. Thus as a robustness test, we removed all first deals made by frequent acquirers and kept only higher order deals. The results remain however very similar even if the first deals account for $40.32 \%$ of the deals made by frequent acquirers (i.e., 354 out of 878 deals, as provided by Panel B and Panel C of Table 1).
} 
decision in the case of infrequent acquirers, but plays no significant role in the frequent acquirers’ sub-sample.

Turning to Panel B of Table 4, where we look at the merger decision while controlling for the target characteristics, we find that, contrary to the results in Panel A, there are no significant differences in terms of performance and TNA between the targets of frequent and infrequent acquirers. Indeed, both groups target poorly performing and small funds. Turnover loads positively in both sub-samples but is highly significant only for the infrequent acquirers, suggesting that the latter tend to target dynamic firms. Both categories of funds target relatively younger funds, but this factor too is critical only for the infrequent acquirers. Flows is equally important for both types of acquirers; they are more likely to target funds with low flows. Fund fees are not different between the targets of frequent acquirers and those of infrequent ones. Overall, these results underscore the importance of controlling for the type of acquirer in the analysis of M\&As in the mutual funds industry, which represents a novel aspect of our study.

**** Insert Table 4 about here****

\subsection{The performance of acquirers and targets: frequent versus infrequent acquirers}

\subsubsection{The pre- and post-merger performance}

Chen et al. (2004) show that fund size is negatively correlated to fund performance. Acquiring another fund and forming a newly combined entity clearly results in larger size for the acquirer. Jayaraman, Khorana, and Nelling (2002) and Ding (2006) find evidence of a decrease in the performance of the acquirer subsequent to an acquisition. Nonetheless, Jayaraman, Khorana, and Nelling (2002) also show a more significant performance reduction for withinfamily mergers compared to cross-family mergers. In a similar fashion, we focus in this section 
on the differences between frequent and infrequent acquirers, and measure for each fund merger the acquirer's fund performance (Alpha) around the merger date. Alpha is based on the riskadjusted alpha of the one-factor (market) and four-factor (Carhart) models. We then run mean and median (Wilcoxon rank sign) tests.

For each acquisition, the Alpha of the acquiring fund is measured before and after the merger date, over three evaluation horizons (12-, 24- and 36-month window lengths). Table 5 reports the mean and median (Wilcoxon rank sign) difference tests. It shows that the acquiring funds experience a significant decrease in performance (at the $1 \%$ level), as measured by the Carhart alpha, subsequent to the acquisition (especially over the 24- and 36-month horizons). These results are in line with Jayaraman, Khorana, and Nelling (2002) and Park (2008), who find deterioration in the acquirer's performance following a fund acquisition. When we split the sample into two groups, frequent and infrequent acquirers respectively, we find weak evidence of underperformance among the frequent acquirers. By contrast, infrequent acquirers exhibit a systematic and significant deterioration over the 12-, 24- and 36-month horizons (almost all coefficients are significant at the $1 \%$ level). This result points to another specificity of frequent acquirers compared to infrequent acquirers, and suggests that the evidence of performance deterioration for the whole sample is mainly driven by the infrequent acquirers.

**** Insert Table 5 about here****

\subsubsection{The acquirer's and target fund's performance}

Evidence in the mutual fund industry suggests that acquirers tend to target more poorly performing funds and keep the fund name/ICDI that has the better performance track record (Ding, 2006). Building on this argument, we expect the acquiring funds to have relatively better performance than their respective targets. Thus, we compare the performances of the acquiring 
funds with their targets' performances before the merger date (using 12-, 24- and 36-month window lengths). For each merger event, we measure the risk-adjusted performance of the acquirer and the target, and compute the difference: acquirer minus target performance.

Table 6 reports the mean and median difference tests. Consistent with the track-record argument, we find that the acquirers perform better than their targets. This result holds for the entire sample, where all the alphas are positive and significant at the $1 \%$ level, and for both frequent and infrequent acquirers. Whether we use the one-factor or the four-factor Alpha, we find that acquirers, regardless of their nature, show better performance than their targets. The only exception is in the infrequent acquirers' sub-sample for the 12-month horizon. ${ }^{8}$

**** Insert Table 6 about here****

\subsubsection{The selection, learning and persistence effects across deals for frequent acquirers}

Across deals, acquirers build track records and reputations, thereby offering more information to potential targets or acquirers. We examine whether the acquisition behaviour of serial acquirers evolves from one acquisition to the next in terms of performance. This issue is examined along three aspects: We first verify whether frequent acquirers become more selective —in terms of their target's past performance-across deals. We call this characteristic the selection effect. Second, we test whether the post-merger performance of frequent acquirers exhibits an upward trend that would support a learning effect across deals. Finally, we verify whether the post-merger performance displays persistence across deals or a reversal pattern. We call this characteristic the persistence effect.

\footnotetext{
${ }^{8}$ In unreported results, we assign both the target and the acquirer to their respective quintiles based on their Alphas, computed using 36 months of returns prior to the merger month. Contrary to the mean and median difference tests, this analysis allows us to capture any potential relationship in the extreme deciles. The Chi-squared test does not reject the null hypothesis of equality across the frequencies for either the entire or the frequent acquirers' sample, but does reject it for the infrequent acquirers' sample.
} 
The selection effect

From deal to deal, acquirer mutual funds could be more reluctant to merge with poorly performing funds and are likely instead to actively select more suitable acquisitions over time. To verify this potential selection effect, we compare the pre-merger performances of the targets of adjacent deals, and run mean and median difference tests on the risk-adjusted performance. Based on the evidence in Table 2, which shows that the frequency of acquisitions per acquirer falls dramatically after the third deal, we restrict the comparison to the first three deals.

Panel A of Table 7 reveals no significant differences in the Alphas between the first and the second deal, or between the second and the third deal, regardless of the considered horizons. This result complements our previous finding in Panel B of Table 2 that there are no marked differences in terms of performance between the targets selected by frequent acquirers and those selected by infrequent acquirers. It seems that, for frequent acquirers, there is no evidence that the target selection process changes across deals.

\section{**** Insert Table 7 about here****}

\section{The learning effect}

We next examine whether there is a learning effect whereby funds tend to improve their post-merger performance, deal by deal. The argument is as follows: Due to higher expertise in pursuing merger transactions and choosing matched funds, the merger transaction should generate increasing value across deals. The corporate M\&A literature stipulates that, when overconfidence induces a higher number of acquisitions, the latter will more likely end up destroying value over time, leading to negative post-merger performance (Fuller, Netter, and Stegemoller, 2002; Ahern, 2008; Croci and Petmezas, 2009). Aktas, De Bodt, and Roll (2012) offer another explanation for post-merger abnormal returns by arguing instead that repetitive 
acquisitions are likely to confer expertise and skills on this acquirer category, and that abnormal returns, as a result, should increase from one deal to another. Boubakri, Chan, and Kooli (2012) also confirm this result.

We test the learning hypothesis in our mutual fund sample. If there is learning across mergers, this should result in a positive risk-adjusted post-merger performance, while an opposite result is more likely to be observed if there is an overconfidence bias. We measure the acquirer post-merger performance of adjacent deals over 12-, 24- and 36-month horizons. We then estimate the mean and the median difference tests for the risk-adjusted performances of each pair of adjacent deals. Because some acquirers carried out a number of acquisitions simultaneously, the number of examined mergers is reduced from 354 to 308 for the second deals, and from 105 to 94 for the third deals.

Panel B of Table 7 reports the empirical results. We find that the risk-adjusted performance indeed decreases from one deal to another, consistent with the existence of an overconfidence bias rather than a learning effect. This deterioration is more important from the first to the second deal and for the 24- and 36-month horizons. Overall, our results thus confirm the existence of an overconfidence bias since funds are likely to achieve lower performance with each subsequent deal (Fuller, Netter, and Stegemoller, 2002; Ahern, 2008; Croci and Petmezas, 2009).

\section{The persistence effect}

We continue to scrutinize the post-merger performance across deals and examine next whether the observed performance exhibits a persistent or a reversal pattern. While the learning effect compares absolute performance measures from one deal to another, we now compare relative (i.e. ranking-based) performance measures. In the previous section, we found that the 
post-merger performance deteriorates across deals. In this section, we examine whether such a downward movement is likely to transport funds from the right to the left side of the crosssectional performance distribution (i.e., reversal), or rather induce movements within the same performance distribution side (i.e., persistence).

Similar to Croci and Petmezas (2009) and in accordance with the mutual fund literature (Brown, Harlow, and Starks, 1996), we analyse the persistence using the contingency approach. Thus, for each deal, we measure the post-merger performance of the combined fund and then compare it to the cross-sectional median performance of all of the funds existing during that period. A fund is categorized as a winner (W) if it holds an above-median performance and as a loser (L) in the opposite case. ${ }^{9}$ We repeat the same method across all of the deals. Then, for each pair of adjacent deals, for example the first and second deals, we are able to obtain a two-by-two frequency matrix of the four contingent states (WW, WL, LW, and LL). We then test the significance of these quantities. We compute the cross-product ratio, (WW*LL)/(WL*LW), and the z-stat, which is the logarithm of the cross-product ratio divided by its standard deviation (Brown and Goetzmann, 1995). The latter is computed as the square root of $(1 / \mathrm{WW}+1 / \mathrm{WL}+1 / \mathrm{LW}+1 / \mathrm{LL})$.

Panel C of Table 7 reports the contingency tables, comparing the first three deals by looking at two successive deals at a time. The results show strong evidence of poor performance persistence across deals. These observations confirm the continuous decrease of performance from deal to deal. We also notice that the observed decrease seems to be confined to the left side of the performance distribution rather than moving from the right to the left side.

\footnotetext{
${ }^{9}$ We also consider another definition of losers and winners: negative and positive risk-adjusted returns. The results remain qualitatively the same.
} 


\subsection{The survival of the acquirer funds}

In this section, we examine whether a fund acquisition influences the survival chance of the acquirer. Due to the complexity of the merger process and potential diseconomies of scale, one would expect the likelihood of survival of the acquiring fund to be negatively affected by the absorption of another fund. Massa and Patgiri (2009) use a parametric model and the Cox semiparametric proportional hazard model to study the impact of the contract structure of portfolio managers on the survival rate of the fund. The authors find a significant positive relation between the risk undertaken by the managers and the exit probability of the fund. Lunde, Timmermann, and Blake (1999) use a Cox regression model to investigate the impact of the fund performance on the probability of the exit of the fund, and find a positive significant relation between these two variables. We contribute to the mutual fund survival literature by analysing here the impact of the merger event on the survival of the fund. Following standards in the mutual fund literature, we consider the parametric logit and semiparametric Cox models to assess the survival patterns of acquirer funds. Compared to parametric models, the Cox duration model leaves the baseline hazard function unspecified and therefore makes no predefined conditions as to the shape of the baseline function. ${ }^{10}$

In the CRSP mutual fund database, the reason for delisting ('delist_cd' column) equals ' $M$ ' for merged funds and ' $L$ ' for delisted funds. If this variable is empty, we do not take the fund into account in our computations, which reduces to some extent the number of funds considered in the present analysis. To investigate the survival issue, we consider the relationship between the survival state and the characteristics of both the acquirer and the target, using the following multinomial logit regression:

\footnotetext{
${ }^{10}$ See Cleves, Gould, Gutierrez, and Marchenko (2008, pages 130-173) for a detailed description of the Cox model.
} 


$$
\begin{gathered}
\text { Survival }_{i, t}=a_{1}+a_{2-7} \text { Acquirer characteristics }_{i, t-k}+a_{8-13} \text { Target }_{\text {characteristics }} \text { A }_{i, t-k}+ \\
+a_{14} \text { Family dummy }_{i, t-k}+a_{15} \text { Frequent acquirer dummy }_{i, t-k}+\varepsilon_{i, t}
\end{gathered}
$$

where $k$ is the survival horizon and equals three years; Survival is an ordinal variable that takes the value 0 if the fund survives, 1 if it is merged into another one and 2 if it is liquidated. ${ }^{11}$ Everything else being equal, we consider the surviving state to be the default state and then test the probability of transit from surviving to merged $\left(\mathrm{P}_{\mathrm{M}} / \mathrm{P}_{\mathrm{S}}\right)$ and then from surviving to liquidated $\left(\mathrm{P}_{\mathrm{L}} / \mathrm{P}_{\mathrm{S}}\right)$. This variable is measured three years after the merger event. We consider the following fund characteristics as defined in Equation (1): fund performance (i.e., Alpha), TNA, Turnover, Fees, Age, and Flows. These variables are measured at the time of the merger. The first set of independent variables includes the acquirer characteristics, while the second set includes the target characteristics. We add two dummy variables: the first is a Family dummy variable that takes the value 1 if the merger in question is an across-family merger and 0 otherwise, and the second is a Frequent acquirer dummy variable that takes the value 1 if the merger involves a frequent acquirer and 0 otherwise. The logistic regression is run using White's adjusted standard errors. Table 8 reports the results of the analysis.

Analysing the survival hypothesis reveals that acquiring another fund has a significant impact on the survival chances of the acquiring fund: First, we find that only a small fraction (76 to be exact) of the acquiring funds have been delisted, as shown in Table 8. Panel A of Table 8 shows the survival frequency distribution for the acquiring funds. In the first three years subsequent to an acquisition, 152 and 20 out of our 1,516 fund acquirers are respectively merged-out and delisted. These numbers reach 255 and 29 respectively, five years after the initial

\footnotetext{
${ }^{11}$ In unreported results, we also consider a five-year horizon and the results remain very similar.
} 
merger. Therefore, the multinomial logit is reduced to a simple logit model between the delisting and survival states and, in our computations, we ignore the funds that have been delisted.

Figure 2 shows a Kaplan-Meier survival curve that depicts a decrease in the survival rate in the five years subsequent to the acquisition, while the infrequent acquirers seem to have a steeper survival slope. This result confirms the findings from Table 5 that frequent acquirers are less affected by merger events and exhibit an insignificant decrease in performance.

\section{***** Insert Figure 2 about here ${ }^{* * * *}$}

Table 8 Panel B shows that not only the acquirer's but also the target's characteristics matter to the survival of the acquiring fund following an acquisition. Among the acquirer characteristics, lower performance, lower inflows and being younger at the time of the merger are all positively linked to the probability of a subsequent exit (column (1)). Moreover, acquiring small and poorly performing funds decrease the probability of the acquirer subsequently being merged out (column (2)). Within-family and frequent acquirers have a higher probability of being merged out (column (3)). We then split the sample into frequent and infrequent acquirers. We find that a poor performance on the part of the acquirer, a younger age and lower fund fees all contribute to decreasing the chances of the frequent acquirer being merged out. Smaller sized and younger targets also decrease the frequent acquirer's chances of being merged out. These variables are significant for both frequent and infrequent acquirers, except that, for the latter, the poor performance and high turnover of the target as well as low inflows on the part of the acquirer increase the probability of the infrequent acquirer being merged out.

\footnotetext{
**** Insert Table 8 about here****
} 
To test the robustness of the logit model results, we use the Cox proportional hazard model, which does not restrict the analysis to a binary variable but instead incorporates the survival duration in the model. Panel $\mathrm{C}$ of Table 8 reports the estimation results and coefficients of the Cox regression. Overall, the results display high consistency with those previously found using the logit model. A decrease in size and a deterioration of performance seem to be continuous-time processes.Splitting the sample into frequent and infrequent acquirers also yields consistent results with those previously found in the logit model and shown in Panel B.

\section{CONCLUDING COMMENTS}

The literature on mutual funds has limited its analysis to two types of mergers: across families and across styles. In this paper, we enrich this literature by making a distinction between mergers involving frequent acquirers and those involving infrequent acquirers, and underline substantial differences between these two fund categories. In particular, we find that fund characteristics such as performance, size, fees, flows and age influence the merger decision and differentiate mergers involving frequent acquirers from those involving infrequent ones. Moreover, from deal to deal, we find that serial acquirers do not exhibit any time-varying pattern in choosing their targets, but display a decreasing trend and persistently poor performance in the post-merger period.

Beyond testing the impact of the merger on subsequent performance, this paper examines the survival consequences. In line with the performance findings, we show that, as frequent acquirers are less affected by acquisitions than are infrequent acquirers, their probability of surviving is higher. Moreover, we find that acquiring a fund that belongs to another family, one that is performing poorly or one that is small-sized increases the acquirer's probability of exit. Equally, a poorly performing or small-sized acquirer also has an increased exit probability. In 
addition, the target's size and performance have a more important impact on the survival of infrequent than frequent acquirer funds.

Finally, though this paper aims to examine various aspects of mutual fund mergers and to bridge the corporate and mutual fund literatures, a number of fruitful research questions remain unanswered. For example, is the decision to merge taken at the family rather than at the fund level? In addition, if this is the case, do mergers create or destroy values in mutual fund families? Is the learning effect present at the family level? Moreover, the issue of cross-border mutual fund M\&As has not yet been addressed by the literature. 


\section{REFERENCES}

Agrawal, Anup, Jeffrey F. Jaffe, and Gershon N. Mandelker, 1992, The post-merger performance of acquiring firms: A re-examination of an anomaly, Journal of Finance 47, $1605-1621$.

Ahern, Kenneth R., 2008, The returns to repeat acquirers, Working paper, University of Michigan.

Aktas, Nihat, Eric De Bodt, and Richard Roll, 2011, Serial acquirer bidding: An empirical test of the learning hypothesis, Journal of Corporate Finance 17, 18-32.

Aktas, Nihat, Eric De Bodt, and Richard Roll, 2012, Learning from repetitive acquisitions: Evidence from the time between deals, Working paper, University of California Los Angeles.

Allen, David E., and Jerry T. Parwada, 2006, Investors' response to mutual fund company mergers, International Journal of Managerial Finance 2, 121-135.

Barber, Brad, and Terrance Odean, 2002, Online investors: Do the slow die first? Review of Financial Studies 15, 455-487.

Betton, Sandra, B. Espen Eckbo, and Karin Thorburn, 2008, Corporate takeovers, Handbook of Corporate Finance: Empirical Corporate Finance 2.

Billett, Matthew T., and Yiming Qian, 2008, Are overconfident managers born or made? Evidence of self-attribution bias from frequent acquirers, Management Science 54, 10371051.

Boubakri, Narjess, Andrew Chan, and Maher Kooli, 2012, Are the busiest really the best? Further evidence from frequent acquirers, Journal of Multinational Financial Management 22, 1-23. 
Brown, Keith C., W. V. Harlow, and Laura T. Starks, 1996, Of tournaments and temptations: An analysis of managerial incentives in the mutual fund industry, Journal of Finance 51, 85110.

Brown, Stephen J., and William N. Goetzmann, 1995, Performance persistence, Journal of Finance 50, 679-698.

Carhart, Mark M., 1997, On persistence in mutual fund performance, Journal of Finance 52, 5782.

Chen, Joseph, Harrison Hong, Ming Huang, and Jeffrey D. Kubik, 2004, Does fund size erode mutual fund performance? The role of liquidity and organization, American Economic Review 94, 1276-1302.

Cleves, Alberto, William Gould, Roberto Gutierrez, and Yulia Marchenko, 2008, An introduction to survival analysis using Stata, $2^{\text {nd }}$ edition, Stata Press.

Croci, Ettore, and Dimitris Petmezas, 2009, Why do managers make serial acquisitions? An investigation of performance predictability in serial acquisitions, Working paper, Universita' Cattolica del Sacro Cuor.

DeYoung, Robert, Douglas Evanoff, and Philip Molyneux, 2009, Mergers and acquisitions of financial institutions: A review of the post-2000 literature, Journal of Financial Services Research 36.

Ding, Bill, 2006, Mutual fund mergers: A long-term analysis, Working paper, SUNY-Albany University.

Doukas, John A., and Dimitris Petmezas, 2007, Acquisitions, overconfident managers and selfattribution bias, European Financial Management 13.

Dutta, Shantanu, Kenneth MacAulay, and Samir Saadi, 2011, CEO power, M\&A decisions, and 
market reactions, Journal of Multinational Financial Management 21, 257-278.

Elton, Edwin J., Martin J. Gruber, and Christopher R. Blake, 1996, The persistence of riskadjusted mutual fund performance, Journal of Business 69, 122-157.

Friesen, Geoffrey, and Paul A. Weller, 2006, Quantifying cognitive biases in analyst earnings forecasts, Journal of Financial Markets 9, 333-365.

Fuller, Kathleen, Jeffry Netter, and Mike Stegemoller, 2002, What do returns to acquiring firms tell us? Evidence from firms that make many acquisitions, Journal of Finance 57, 17631793.

Gargouri, Ines, and Lawrence Kryzanowski, 2011, US mutual fund M\&As, Working paper, Concordia University.

Gaughan, Patrick A., 2011, Mergers, acquisitions, and corporate restructurings, 5th edition, John Wiley \& Sons.

Grinblatt, Mark, and Matti Keloharju, 2009, Sensation seeking, overconfidence, and trading activity, The Journal of Finance 64, 549-578.

Horst, Jenke R. ter, Theo E. Nijman, and Marno Verbeek, 2001, Eliminating look-ahead bias in evaluating persistence in mutual fund performance, Journal of Empirical Finance 8, 121152.

Hsu, Yenshan, and Cheng-Yi Shiu, 2010, The overconfidence of investors in the primary market, Pacific-Basin Finance Journal 18, 217-239.

Investment Company Institute, 2011, Investment Company Fact Book.

Jayaraman, Narayanan, Ajay Khorana, and Edward Nelling, 2002, An analysis of the determinants and shareholder wealth effects of mutual fund mergers, Journal of Finance 57, 1521-1551. 
Jensen, Michael, 1988, Association takeovers: Their causes and consequences, Journal of Economic Perspectives 2, 21-48.

Khorana, Ajay, Peter Tufano, and Lei Wedge, 2007, Board structure, mergers, and shareholder wealth: A study of the mutual fund industry, Journal of Financial Economics 85, 571598.

Kothari, S.P., and Jerold B. Warner, 2001, Evaluating mutual fund performance, Journal of Finance 56, 1985-2010.

Lin, Bing-Xuan, David Michayluk, Henry R. Oppenheimer, and Sean F. Reid, 2008, Hubris amongst Japanese bidders, Pacific-Basin Finance Journal 16, 121-159.

Lunde, Asger, Allan Timmermann, and David Blake, 1999, The hazards of mutual fund underperformance: A Cox regression analysis, Journal of Empirical Finance 6, 121-152.

Malkiel, Burton G., 1995, Returns from investing in equity mutual funds, Journal of Finance 50, 549-572.

Malmendier, Ulrike, and Geoffrey Tate, 2005, CEO overconfidence and corporate investment, Journal of Finance 60, 2661-2700.

Martynova, Marina, and Luc Renneboog, 2008, A century of corporate takeovers: What have we learned and where do we stand? Journal of Banking and Finance 32, 2148-2177.

Massa, Massimo, and Rajdeep Patgiri, 2009, Incentives and mutual fund performance: Higher performance or just higher risk taking? Review of Financial Studies 22, 1777-1815.

Park, Minjung, 2008, An empirical two-sided matching model of acquisitions: Understanding merger incentives and outcomes in the mutual fund industry, Working paper, University of Minnesota.

Petersen, Mitchell A., 2009, Estimating standard errors in finance panel data sets: Comparing 
approaches, Review of Financial Studies 22, 435-480.

Rosen, Richard J., 2005, Betcha can't acquire just one: Merger programs and compensation, Working paper, Federal Reserve Bank of Chicago 2004-22

Smith, David M., 2009, The economics of mutual funds, Haslem, J. (Ed.), Mutual Funds: Portfolio Structures, Analysis, Management, and Stewardship. Wiley, New York 33-49.

Thompson, Samuel B., 2011, Simple formulas for standard errors that cluster by both firm and time, Journal of Financial Economics 99, 1-10.

Zhao, Xinge 2005, Exit decisions in the U.S. mutual fund industry, Journal of Business 78, 1365-1401. 


\section{Figure 1}

The number and value of fund mergers over the period 1965-2010

This figure depicts the number of fund mergers each year in our sample (left axis) and the value of the deals in billions of \$ (right axis). The x-axis displays the years and the y-axis reports the merger numbers and value.

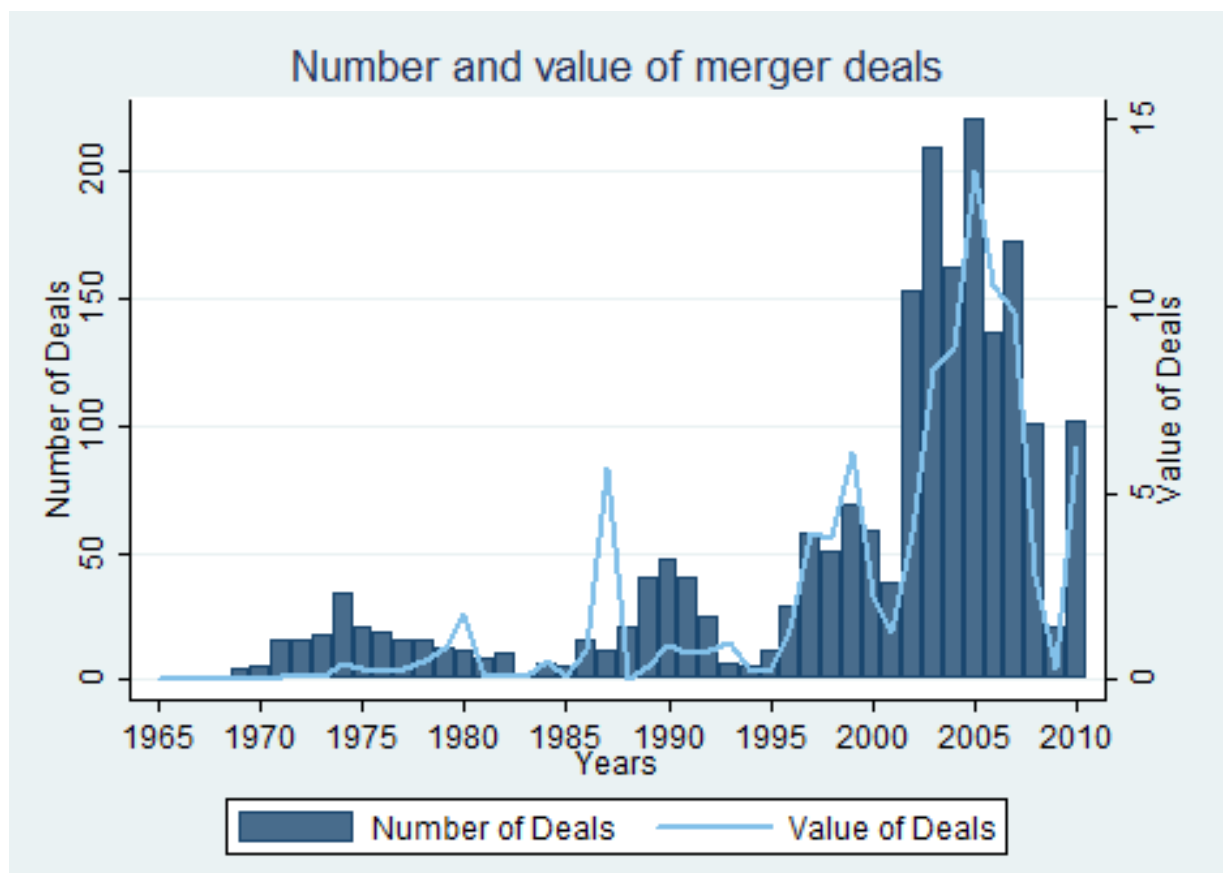


Figure 2

The Kaplan-Meier probability of survival after a fund acquisition

This figure depicts the Kaplan-Meier survival curve of the acquiring funds up to five years after an acquisition. The continuous (dashed) curve shows the survival rate $T$ months after the merger for the infrequent (frequent) acquirers.

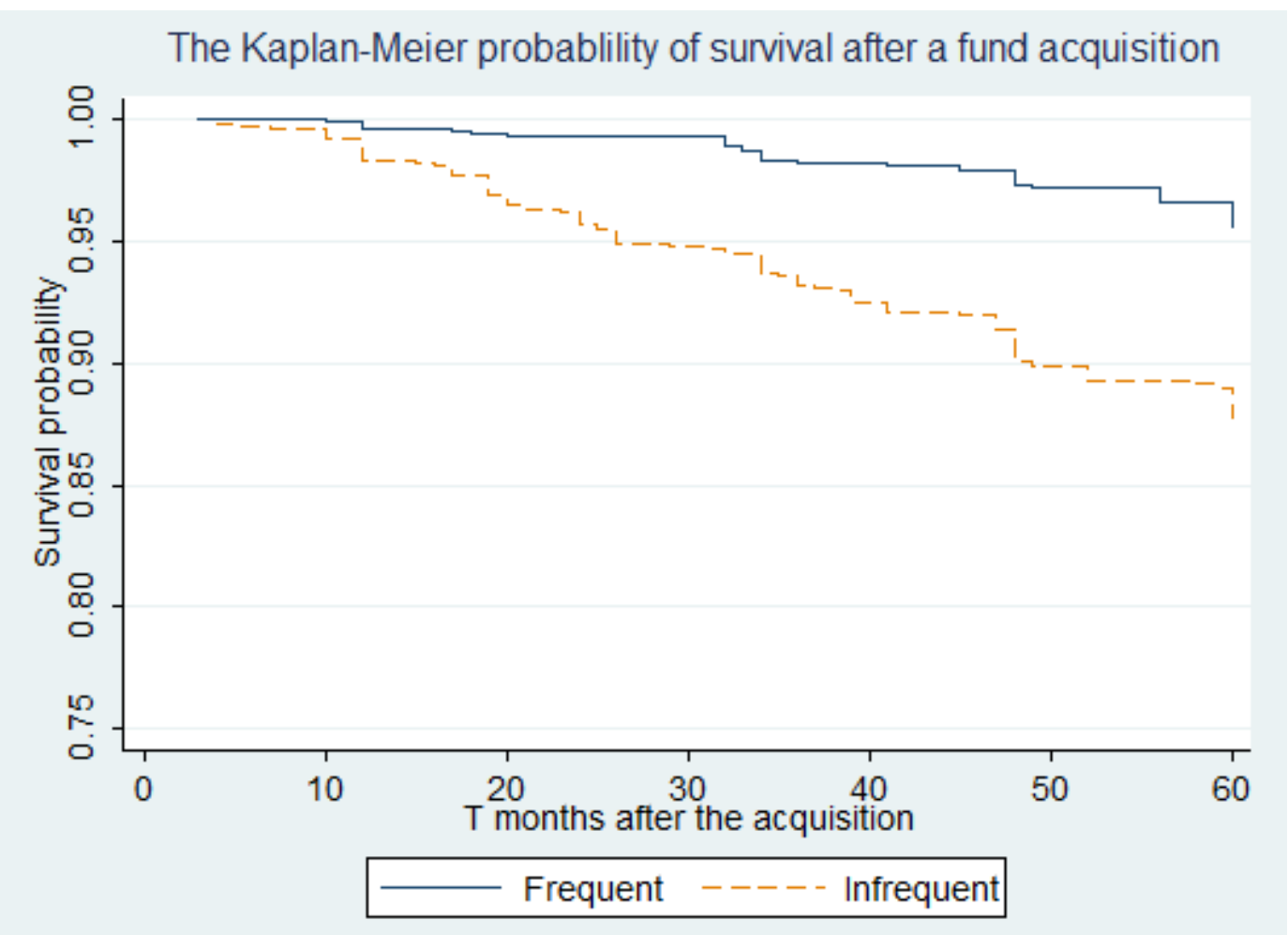


Table 1

Descriptive statistics

Table 1 displays descriptive statistics regarding our sample of mutual funds and their mergers. Panel A displays the total net assets (TNA in millions of \$) of the all the deals (i.e. target's TNA) in our sample and the average TNA of the equity fund industry (based on Table 3, page 130 of the ICI fact book, 2011) in different time periods. Column 3 reports the ratio of the target TNA to all the equity funds' TNAs. The last column displays the number of mergers i.e. the number of deals in the given year. Panel B shows the frequency distribution of the number of acquisitions. The number of acquisitions is reported in the first column, while columns 2 and 3 show the number of acquirers-both absolute and relative frequencies-for the corresponding number of acquisitions. The size of the target (i.e. the deal amount), in both absolute and relative values, are displayed in columns 4 and 5. Panel C displays summarized statistics about the frequent and infrequent acquirers, where frequent acquirers are defined as funds that acquired more than one fund and infrequent those that acquired only one fund. The first and second columns report the absolute and relative numbers of frequent and infrequent acquirers. The third and fourth columns report the absolute and relative number of deals for frequent and infrequent acquirers, while the fifth and sixth columns report the absolute and relative TNAs of the deals for frequent and infrequent acquirers.

Panel A: Annual descriptive statistics on mutual fund mergers

\begin{tabular}{crrrr}
\hline Years & \multicolumn{1}{c}{$\begin{array}{c}\text { Target TNA } \\
\text { in \$m }\end{array}$} & $\begin{array}{c}\text { Total equity } \\
\text { fund TNA in \$m }\end{array}$ & Target TNA/Total Fund & Number of deals \\
\hline $1965-1980$ & $4,218.6$ & $38,382.4$ & $10.99 \%$ & 193 \\
$1981-1990$ & $8,732.6$ & $136,664.5$ & $6.39 \%$ & 173 \\
$1991-2000$ & $20,586.5$ & $1,883,711.9$ & $1.09 \%$ & 356 \\
$2001-2010$ & $66,475.3$ & $4,585,170.6$ & $1.45 \%$ & 1,318 \\
\hline
\end{tabular}

Panel B: Distribution of the number of acquisitions

\begin{tabular}{crrrr}
\hline Number of acquisitions & \# of Acquirers & Acquirers in $\%$ & TNA of deals & TNA in \% \\
\hline 1 & 1,162 & $76.6 \%$ & $52,816.3$ & $52.8 \%$ \\
2 & 249 & $16.4 \%$ & $18,175.7$ & $18.2 \%$ \\
3 & 65 & $4.3 \%$ & $14,208.0$ & $14.2 \%$ \\
4 & 28 & $1.8 \%$ & $9,895.8$ & $9.9 \%$ \\
5 & 5 & $0.3 \%$ & $2,325.6$ & $2.3 \%$ \\
6 & 4 & $0.3 \%$ & $1,754.9$ & $1.8 \%$ \\
7 & 1 & $0.1 \%$ & 447.2 & $0.4 \%$ \\
8 & 1 & $0.1 \%$ & 296.4 & $0.3 \%$ \\
9 & 1 & $0.1 \%$ & 93.1 & $0.1 \%$ \\
\hline Total & 1,516 & $100.0 \%$ & $100,013.0$ & $100 \%$ \\
\hline
\end{tabular}

Panel C: Frequent and infrequent acquirer funds

\begin{tabular}{|c|c|c|c|c|c|c|}
\hline & $\begin{array}{l}\text { Number of } \\
\text { Acquirers }\end{array}$ & $\begin{array}{c}\text { Acquirers in } \\
\%\end{array}$ & $\begin{array}{c}\text { Number of } \\
\text { Deals }\end{array}$ & Deals in \% & $\begin{array}{l}\text { Value of Deals } \\
\text { in } \$ \mathrm{~m}\end{array}$ & $\begin{array}{l}\text { Value of } \\
\text { Deals in \% }\end{array}$ \\
\hline Infrequent acquirers & 1,162 & $76.6 \%$ & 1,162 & $57.0 \%$ & $52,816.3$ & $52.8 \%$ \\
\hline Frequent acquirers & 354 & $23.4 \%$ & 878 & $43.0 \%$ & $47,196.7$ & $47.2 \%$ \\
\hline Total & 1,516 & $100.0 \%$ & 2,040 & $100.0 \%$ & $100,013.0$ & $100.0 \%$ \\
\hline
\end{tabular}




\section{Table 2}

Statistics on frequent, infrequent, within- and across-family mergers

Panel A reports a frequency table of mutual fund mergers; we categorize the mergers into deals involving frequent and infrequent acquirers, and into within- and across-family acquisitions. Panel B reports the characteristics of the top ten merger transactions: acquirer and target fund names, the TNA of the target fund, the year of the merger, whether the acquirer fund is a frequent or an infrequent acquirer, and whether it is a within- or an across-family merger.

\section{Panel A Frequency distribution}

\begin{tabular}{|l|c|c|c|}
\hline & Within-family & Across-family & Total \\
\hline Frequent & 306 & 572 & 878 \\
\hline Infrequent & 653 & 509 & 1,162 \\
\hline Total & 959 & 1,081 & 2,040 \\
\hline
\end{tabular}

\section{Panel B Top ten fund merger transactions}

\begin{tabular}{|c|c|c|c|c|c|c|}
\hline Rank & Target fund & Acquiring Fund & $\begin{array}{c}\text { Target } \\
\text { TNA in \$m }\end{array}$ & Year & $\begin{array}{l}\text { Frequent or } \\
\text { Infrequent }\end{array}$ & $\begin{array}{l}\text { Within- or } \\
\text { across-family }\end{array}$ \\
\hline 1 & Hutton AMA Cash Fund & Shearson Daily Dividend & $3,758.3$ & 1994 & Frequent & across \\
\hline 2 & Cash Reserve Management Trust & Shearson Daily Dividend & $3,481.3$ & 1994 & Frequent & across \\
\hline 3 & Lehman Mgmt-Gov't Reserve & Shearson Gov't \& Agencies & $1,712.0$ & 1994 & Frequent & across \\
\hline 4 & Hutton Gov't Fund & Shearson Gov't \& Agencies & $1,190.2$ & 1994 & Frequent & across \\
\hline 5 & Woodward Growth Value & One Group Diversified Equity Fund & $1,146.5$ & 2005 & Infrequent & across \\
\hline 6 & $\begin{array}{l}\text { IDS Research Opportunities } \\
\text { Fund/A }\end{array}$ & AXP Growth Series: RiverSource Large Cap Equity & 957.1 & 2009 & Frequent & across \\
\hline 7 & IDS Blue Chip Advantage & AXP Growth Series: AXP Large Cap Equity Fund & 829.7 & 2009 & Frequent & across \\
\hline 8 & State Street Research Galileo & BlackRock Funds: Select Equity Portfolio & 664.7 & 2007 & Frequent & across \\
\hline 9 & IDS Research Opportunities & AXP Growth Series, Inc: AXP Large Cap Equity & 596.7 & 2009 & Frequent & across \\
\hline 10 & WM Trust I: Growth \& Income & Principal Funds, Inc: Disciplined LargeCap Blend & 581.4 & 2006 & Infrequent & across \\
\hline
\end{tabular}


Table 3

The determinants of the merger decision

Table 3 reports the results of the determinants of the merger decision for the acquirer and the merger occurrence for the target. Panel A displays the logit regression results of Equation (1), where the dummy variable Merger Dummy is regressed on the acquirer characteristics: the total net assets (TNA), past performance Alpha 12, 24 and 36 months, Age, Turnover and Fees. The dependent variable Merger Dummy takes the value of 1 if the fund made an acquisition at time $t$ and 0 if not. Panel B shows the logit regression results of Equation (1), where the dummy variable Merger Dummy is regressed on the target characteristics as defined above. The dependent variable Merger Dummy takes the value of 1 if the fund was acquired at that date and 0 if not. Coefficients are reported in the first lines and t-stats are in parentheses. ${ }^{* *},{ }^{* *}$, and $*$ indicate significance at the $0.01,0.05$, and 0.10 levels, respectively.

Panel A Acquirer characteristics

\begin{tabular}{|c|c|c|c|c|c|c|}
\hline & $(1)$ & $(2)$ & $(3)$ & (4) & $(5)$ & (6) \\
\hline \multirow[t]{2}{*}{ Alpha $_{12 \text { months }}$} & -12.558 & $-18.115^{*}$ & & & & \\
\hline & $(-1.61)$ & $(-1.92)$ & & & & \\
\hline \multirow[t]{2}{*}{ Alpha $_{24 \text { months }}$} & & & $-21.345^{*}$ & $-27.251^{* *}$ & & \\
\hline & & & $(-1.83)$ & $(-2.37)$ & & \\
\hline \multirow[t]{2}{*}{ Alpha 36 months } & & & & & $-28.576^{*}$ & $-31.640 * *$ \\
\hline & & & & & $(-1.88)$ & $(-2.29)$ \\
\hline \multirow[t]{2}{*}{$\ln (T N A)$} & & -0.049 & & -0.045 & & -0.028 \\
\hline & & $(-1.47)$ & & $(-1.42)$ & & $(-0.85)$ \\
\hline \multirow[t]{2}{*}{ Turnover } & & 10.853 & & 11.354 & & 10.915 \\
\hline & & $(1.28)$ & & $(1.49)$ & & $(1.47)$ \\
\hline \multirow[t]{2}{*}{ Fees } & & -0.025 & & -0.029 & & -0.027 \\
\hline & & $(-0.37)$ & & $(-0.36)$ & & $(-0.31)$ \\
\hline \multirow[t]{2}{*}{ Age } & & $-0.030 * * *$ & & $-0.031 * * *$ & & $-0.031 * * *$ \\
\hline & & $(-5.85)$ & & $(-5.74)$ & & $(-5.66)$ \\
\hline \multirow[t]{2}{*}{ Flows } & & 0.000 & & 0.000 & & 0.000 \\
\hline & & $(0.85)$ & & $(0.32)$ & & $(0.49)$ \\
\hline \multirow[t]{2}{*}{ Intercept } & $-2.511 * * *$ & $-2.057 * * *$ & $-2.532 * * *$ & $-2.046 * * *$ & $-2.541 * * *$ & $-2.098^{* * *}$ \\
\hline & $(-19.29)$ & $(-8.55)$ & $(-17.67)$ & $(-8.89)$ & $(-17.03)$ & $(-7.88)$ \\
\hline Pseudo $R^{2}$ & $0.15 \%$ & $2.58 \%$ & $0.21 \%$ & $2.68 \%$ & $0.27 \%$ & $2.61 \%$ \\
\hline \# of observations & 20,721 & 16,198 & 19,185 & 15,699 & 17,725 & 14,879 \\
\hline
\end{tabular}


Panel B Target characteristics

\begin{tabular}{|c|c|c|c|c|c|c|}
\hline & (1) & (2) & (3) & (4) & (5) & (6) \\
\hline \multirow[t]{2}{*}{ Alpha $_{12 \text { months }}$} & $-33.642 * * *$ & $-25.993 * * *$ & & & & \\
\hline & $(-4.74)$ & $(-2.97)$ & & & & \\
\hline \multirow[t]{2}{*}{ Alpha 24 months } & & & $-75.219 * * *$ & $-53.761^{* * *}$ & & \\
\hline & & & $(-6.17)$ & $(-3.94)$ & & \\
\hline \multirow[t]{2}{*}{ Alpha 36 months } & & & & & $-110.229 * * *$ & $-91.806^{* * *}$ \\
\hline & & & & & $(-5.52)$ & $(-4.39)$ \\
\hline \multirow[t]{2}{*}{$\ln (T N A)$} & & $-0.254 * * *$ & & $-0.251 * * *$ & & $-0.246 * * *$ \\
\hline & & $(-7.50)$ & & $(-7.58)$ & & $(-7.29)$ \\
\hline \multirow[t]{2}{*}{ Turnover } & & $21.982 *$ & & 12.669 & & 10.348 \\
\hline & & $(1.75)$ & & $(0.99)$ & & $(0.86)$ \\
\hline \multirow[t]{2}{*}{ Fees } & & -0.009 & & -0.038 & & -0.082 \\
\hline & & $(-0.17)$ & & $(-0.85)$ & & $(-1.31)$ \\
\hline \multirow[t]{2}{*}{ Age } & & -0.004 & & -0.007 & & -0.008 \\
\hline & & $(-0.64)$ & & $(-1.10)$ & & $(-1.31)$ \\
\hline \multirow[t]{2}{*}{ Flows } & & $-0.008 * * *$ & & $-0.008 * * *$ & & $-0.007^{*}$ \\
\hline & & $(-2.89)$ & & $(-2.76)$ & & $(-1.67)$ \\
\hline \multirow[t]{2}{*}{ Intercept } & $-1.684 * * *$ & $-1.063 * * *$ & $-1.591 * * *$ & $-0.813 * * *$ & $-1.514^{* * *}$ & $-0.662 * *$ \\
\hline & $(-9.33)$ & $(-3.97)$ & $(-9.67)$ & $(-2.95)$ & $(-9.32)$ & $(-2.53)$ \\
\hline Pseudo $R^{2}$ & $8.94 \%$ & $4.94 \%$ & $7.48 \%$ & $3.23 \%$ & $6.64 \%$ & $1.29 \%$ \\
\hline \# of observations & 11,569 & 7,861 & 9,664 & 7,199 & 8,032 & 6,265 \\
\hline
\end{tabular}


Table 4

The determinants of mergers by frequent and infrequent acquirers

Table 4 reports the results for whether the mergers involve frequent or infrequent acquirers. Panel A displays the multinomial logit regression results for Equation (3), where Frequent Merger is a dummy variable that equals 0 if the fund is not involved in a merger, 1 if the acquisition involves a frequent acquirer and 2 if it involves an infrequent acquirer. This dummy variable is regressed on the acquirer characteristics in Panel A and the target characteristics in Panel B. The fund characteristics are the total net assets (TNA), past performance: Alpha 12, 24 and 36 months, Age, Turnover, Fees, and a Dummy family which is a dummy variable equal to 1 if it is a withinfamily merger and 0 if not. Coefficients are reported in the first lines and $\mathrm{t}$-stats in parentheses. ***, **, and * indicate significance at the $0.01,0.05$, and 0.10 levels, respectively.

Panel A Acquirer characteristics

\begin{tabular}{|c|c|c|c|c|c|c|}
\hline & \multicolumn{2}{|c|}{$(1)$} & \multicolumn{2}{|c|}{ (2) } & \multicolumn{2}{|c|}{ (3) } \\
\hline & Frequent & Infrequent & Frequent & Infrequent & Frequent & Infrequent \\
\hline \multirow[t]{2}{*}{ Alpha 12 months } & -0.965 & $-19.743^{* * *}$ & & & & \\
\hline & $(-0.14)$ & $(-4.58)$ & & & & \\
\hline \multirow[t]{2}{*}{ Alpha 24 months } & & & 12.489 & $-37.798 * * *$ & & \\
\hline & & & $(1.20)$ & $(-5.68)$ & & \\
\hline \multirow[t]{2}{*}{ Alpha 36 months } & & & & & 5.967 & $-36.121 * * *$ \\
\hline & & & & & $(0.47)$ & $(-4.29)$ \\
\hline \multirow[t]{2}{*}{$\ln (T N A)$} & 0.015 & $-0.059 * *$ & 0.018 & $-0.053 * *$ & 0.022 & -0.030 \\
\hline & $(0.45)$ & $(-2.49)$ & $(0.54)$ & $(-2.16)$ & $(0.62)$ & $(-1.20)$ \\
\hline \multirow[t]{2}{*}{ Turnover } & -6.838 & $17.314^{* *}$ & -2.429 & $16.620 * *$ & -11.940 & $20.038 * * *$ \\
\hline & $(-0.64)$ & $(2.48)$ & $(-0.22)$ & $(2.26)$ & $(-1.00)$ & $(2.60)$ \\
\hline \multirow[t]{2}{*}{ Fees } & $0.219 * * *$ & $-0.154 * * *$ & $0.218 * * *$ & $-0.166 * * *$ & $0.202 * * *$ & $-0.147 * *$ \\
\hline & $(4.60)$ & $(-2.79)$ & $(4.51)$ & $(-2.94)$ & (3.83) & $(-2.50)$ \\
\hline \multirow[t]{2}{*}{ Age } & $-0.010 * *$ & $-0.051 * * *$ & $-0.010 * *$ & $-0.053 * * *$ & $-0.010 * *$ & $-0.055^{* * *}$ \\
\hline & $(-2.07)$ & $(-8.99)$ & $(-2.04)$ & $(-8.72)$ & $(-2.00)$ & $(-8.43)$ \\
\hline \multirow[t]{2}{*}{ Flows } & -0.000 & $0.000 *$ & $-0.001^{*}$ & 0.000 & -0.001 & 0.000 \\
\hline & $(-1.20)$ & (1.93) & $(-1.71)$ & (1.31) & $(-1.51)$ & (1.30) \\
\hline \multirow[t]{2}{*}{ Intercept } & $-3.861 * * *$ & $-2.209 * * *$ & $-3.973 * * *$ & $-2.153^{* * *}$ & $-3.852 * * *$ & $-2.292 * * *$ \\
\hline & $(-15.03)$ & $(-12.62)$ & $(-14.83)$ & $(-11.63)$ & $(-13.57)$ & $(-11.59)$ \\
\hline Pseudo $R^{2}$ & \multicolumn{2}{|c|}{$3.10 \%$} & \multicolumn{2}{|c|}{$3.30 \%$} & \multicolumn{2}{|c|}{$3.20 \%$} \\
\hline \# of observations & \multicolumn{2}{|c|}{17,027} & \multicolumn{2}{|c|}{16,521} & \multicolumn{2}{|c|}{15,701} \\
\hline
\end{tabular}


Panel B Target characteristics

\begin{tabular}{|c|c|c|c|c|c|c|}
\hline & \multicolumn{2}{|c|}{ (1) } & \multicolumn{2}{|c|}{ (2) } & \multicolumn{2}{|c|}{ (3) } \\
\hline & Frequent & Infrequent & Frequent & Infrequent & Frequent & Infrequent \\
\hline \multirow[t]{2}{*}{ Alpha 12 months } & $-21.426 * * *$ & $-29.701^{* * *}$ & & & & \\
\hline & $(-4.12)$ & $(-6.63)$ & & & & \\
\hline \multirow[t]{2}{*}{ Alpha 24 months } & & & $-44.347 * * *$ & $-60.112 * * *$ & & \\
\hline & & & $(-5.38)$ & $(-8.11)$ & & \\
\hline \multirow[t]{2}{*}{ Alpha $_{36 \text { months }}$} & & & & & $-71.598 * * *$ & $-104.768 * * *$ \\
\hline & & & & & $(-6.27)$ & $(-9.85)$ \\
\hline \multirow[t]{2}{*}{$\ln (T N A)$} & $-0.267 * * *$ & $-0.228 * * *$ & $-0.264 * * *$ & $-0.226 * * *$ & $-0.253^{* * *}$ & $-0.224 * * *$ \\
\hline & $(-7.90)$ & $(-7.77)$ & $(-7.68)$ & $(-7.48)$ & $(-6.83)$ & $(-7.00)$ \\
\hline \multirow[t]{2}{*}{ Turnover } & $14.376 *$ & $28.248^{* * *}$ & 4.182 & $19.444^{* *}$ & 2.050 & $17.332 * *$ \\
\hline & $(1.80)$ & (3.81) & $(0.49)$ & (2.48) & $(0.22)$ & (2.09) \\
\hline \multirow[t]{2}{*}{ Fees } & -0.010 & -0.007 & -0.034 & -0.039 & -0.056 & -0.103 \\
\hline & $(-0.16)$ & $(-0.13)$ & $(-0.52)$ & $(-0.69)$ & $(-0.80)$ & $(-1.46)$ \\
\hline \multirow[t]{2}{*}{ Age } & 0.003 & $-0.011^{* *}$ & -0.000 & $-0.015 * * *$ & -0.001 & $-0.016 * * *$ \\
\hline & $(0.67)$ & $(-2.37)$ & $(-0.04)$ & $(-2.84)$ & $(-0.27)$ & $(-2.88)$ \\
\hline \multirow[t]{2}{*}{ Flows } & $-0.011 * * *$ & $-0.006 * * *$ & $-0.009 * * *$ & $-0.007 * * *$ & $-0.009 * *$ & $-0.005^{*}$ \\
\hline & $(-3.47)$ & $(-2.60)$ & $(-2.68)$ & $(-2.71)$ & $(-2.03)$ & $(-1.83)$ \\
\hline \multirow[t]{2}{*}{ Intercept } & $-1.859 * * *$ & $-1.765^{* * *}$ & $-1.591 * * *$ & $-1.518^{* * *}$ & $-1.516^{* * *}$ & $-1.326 * * *$ \\
\hline & $(-9.28)$ & $(-9.66)$ & $(-7.49)$ & $(-7.76)$ & $(-6.37)$ & $(-6.27)$ \\
\hline Pseudo $R^{2}$ & \multicolumn{2}{|c|}{$5.40 \%$} & \multicolumn{2}{|c|}{$6.00 \%$} & \multicolumn{2}{|c|}{$7.20 \%$} \\
\hline \# of observations & \multicolumn{2}{|c|}{8,005} & \multicolumn{2}{|c|}{7,331} & \multicolumn{2}{|c|}{6,390} \\
\hline
\end{tabular}




\section{Table 5}

The performance of the acquirer fund before and after the acquisition

This table reports the mean and median difference tests of the acquirer's performance before and after the merger. We rely on the one- and four-factor alphas to assess the fund performance 12, 24 and 36 months before and after the merger month. The first two columns report the results for the entire sample, columns (3) and (4) report the results for the frequent acquirer group and columns (5) and (6) report those for the infrequent acquirer group. For each horizon, the first lines report the mean difference i.e. the performance after the merger minus the performance before the merger, the second lines report the p-value of the mean t-test, and the third lines report the p-value of a Wilcoxon rank sign test i.e. a median difference test. ***, $* *$, and $*$ indicate significance at the 0.01 , 0.05 , and 0.10 levels, respectively, based on the mean test $p$-value.

\begin{tabular}{|c|c|c|c|c|c|c|}
\hline \multirow[b]{2}{*}{ Horizon } & \multicolumn{2}{|c|}{$\begin{array}{l}\text { All funds } \\
\end{array}$} & \multicolumn{2}{|c|}{$\begin{array}{c}\text { Frequent } \\
\end{array}$} & \multicolumn{2}{|c|}{ Infrequent } \\
\hline & Alpha 1-factor & Alpha 4-factor & Alpha 1-factor & Alpha 4-factor & Alpha 1-factor & Alpha 4-factor \\
\hline \multirow[t]{3}{*}{12 months } & $-0.0009 * *$ & -0.0004 & -0.0008 & 0.0004 & $-0.0010^{* *}$ & $-0.0011^{* * *}$ \\
\hline & 0.02 & 0.18 & 0.16 & 0.45 & 0.05 & 0.01 \\
\hline & 0.02 & 0.61 & 0.14 & 0.71 & 0.07 & 0.28 \\
\hline \multirow[t]{3}{*}{24 months } & $-0.0013 * * *$ & $-0.0005^{* *}$ & -0.0004 & 0.0003 & $-0.0021^{* * *}$ & $-0.0011^{* * *}$ \\
\hline & 0.00 & 0.04 & 0.29 & 0.39 & 0.00 & 0.00 \\
\hline & 0.01 & 0.57 & 0.52 & 0.93 & 0.00 & 0.51 \\
\hline \multirow[t]{3}{*}{36 months } & $-0.0016 * * *$ & $-0.0009 * * *$ & $-0.0010^{* * *}$ & -0.0004 & $-0.0022 * * *$ & $-0.0013^{* * *}$ \\
\hline & 0.00 & 0.00 & 0.00 & 0.15 & 0.00 & 0.00 \\
\hline & 0.00 & 0.00 & 0.02 & 0.00 & 0.00 & 0.00 \\
\hline
\end{tabular}




\section{Table 6}

The difference between the acquirer's and the target fund's performance

Table 6 reports the mean and median performance differences test between the acquirer and the target before the merger. We rely on the one- and four-factor alphas to assess the funds' performance 12, 24 and 36 months before the merger occurrence month. The first two columns report the results for the entire sample, columns (3) and (4) report the results for the frequent acquirer group and columns (5) and (6) report those for the infrequent acquirer group. For each horizon, the first lines report the mean difference i.e. the performance of the acquirer before the merger minus the performance of the target before the merger, the second lines report the p-value of the mean t-test, and the third lines report the p-value of a Wilcoxon rank sign test i.e. a median difference test. ***, **, and $*$ indicate significance at the $0.01,0.05$, and 0.10 levels, respectively, based on the mean test $p$-value.

\begin{tabular}{|c|c|c|c|c|c|c|}
\hline \multirow[b]{2}{*}{ Horizon } & \multicolumn{2}{|c|}{ All funds } & \multicolumn{2}{|c|}{ Frequent } & \multicolumn{2}{|c|}{ Infrequent } \\
\hline & Alpha 1-factor & Alpha 4-factor & Alpha 1-factor & Alpha 4-factor & Alpha 1-factor & Alpha 4-factor \\
\hline \multirow[t]{3}{*}{12 months } & $0.0036^{* * *}$ & $0.0031^{* * *}$ & $0.0036 * * *$ & $0.0028 * * *$ & 0.0009 & 0.0004 \\
\hline & 0.00 & 0.00 & 0.00 & 0.00 & 0.32 & 0.61 \\
\hline & 0.43 & 0.07 & 0.33 & 0.07 & 0.02 & 0.01 \\
\hline \multirow[t]{3}{*}{24 months } & $0.0039 * * *$ & $0.0032^{* * *}$ & $0.0036^{* * *}$ & $0.0032^{* * *}$ & $0.0028 * * *$ & $0.0013^{* *}$ \\
\hline & 0.00 & 0.00 & 0.00 & 0.00 & 0.00 & 0.04 \\
\hline & 0.03 & 0.00 & 0.02 & 0.01 & 0.10 & 0.81 \\
\hline \multirow[t]{3}{*}{36 months } & $0.0037^{* * *}$ & $0.0027^{* * *}$ & $0.0035^{* * *}$ & $0.0026^{* * *}$ & $0.0035 * * *$ & $0.0021^{* * *}$ \\
\hline & 0.00 & 0.00 & 0.00 & 0.00 & 0.00 & 0.00 \\
\hline & 0.00 & 0.00 & 0.00 & 0.00 & 0.00 & 0.15 \\
\hline
\end{tabular}




\section{Table 7}

Selection, learning and persistence from deal to deal for frequent acquirers

Panel A reports the mean and median difference tests between the performances of the first and second targets (second minus first), and the second and third targets (third minus second) of the same acquirer in the 12, 24 and 36 months before the merger occurrence month. Panel B reports the mean and median difference tests of the post-merger performance of the acquirer between the first and second deals (second minus first), and the second and third deals (third minus second). Panel C reports the persistence tests of the post-merger performance of the acquirer between the first and second deals, and the second and third deals. For each deal, the fund is assigned to an above-the-median (W) or under-the-median (L) post-merger performance group. Then, for each pair of deals, we form four groups based on their performance rankings (LL, LW, WL, WW). We rely on the one- and four-factor alphas to assess the funds' performances. ***, **, and * indicate significance at the $0.01,0.05$, and 0.10 levels, respectively, based on the mean test p-value.

Panel A Selection of targets across deals (Pre-merger performance)

\begin{tabular}{lcccc}
\cline { 2 - 5 } & \multicolumn{2}{c}{ First vs. Second } & \multicolumn{2}{c}{ Second vs. Third } \\
\cline { 2 - 5 } Alpha 1-factor & Alpha 4-factor & Alpha 1-factor & Alpha 4-factor \\
\hline \multirow{3}{*}{2 months } & 0.0025 & -0.0004 & 0.0005 & 0.0001 \\
& 0.24 & 0.88 & 0.86 & 0.97 \\
& 0.30 & 0.97 & 0.45 & 0.33 \\
36 months & 0.0014 & 0.0009 & -0.0023 & -0.0015 \\
& 0.44 & 0.58 & 0.42 & 0.54 \\
& 0.33 & 0.21 & 0.81 & 0.95 \\
& 0.0013 & 0.0007 & -0.0044 & -0.0035 \\
& 0.41 & 0.68 & 0.16 & 0.28 \\
& 0.28 & 0.62 & 0.55 & 0.52 \\
\hline
\end{tabular}

Panel B Learning across deals (Post-merger performance)

\begin{tabular}{lcccc}
\cline { 2 - 5 } & \multicolumn{2}{c}{ First vs. Second } & \multicolumn{2}{c}{ Second vs. Third } \\
\cline { 2 - 5 } 12 months & Alpha 1-factor & Alpha 4-factor & Alpha 1-factor & Alpha 4-factor \\
& -0.0008 & 0.0003 & -0.0003 & -0.0025 \\
\multirow{3}{*}{24 months } & 0.74 & 0.39 & 0.83 & 0.82 \\
& 0.14 & 0.84 & 0.89 & 0.24 \\
\multirow{3}{*}{36 months } & $-0.0013^{* * *}$ & $-0.0017^{* * *}$ & $-0.0001^{*}$ & -0.0007 \\
& 0.03 & 0.01 & 0.18 & 0.30 \\
& 0.01 & 0.02 & 0.10 & 0.11 \\
& $-0.0015^{* * *}$ & $-0.0008^{* * *}$ & -0.0010 & $-0.0005^{* * *}$ \\
& 0.05 & 0.03 & 0.08 & 0.04 \\
\hline
\end{tabular}


Panel C Post-merger performance persistence

\begin{tabular}{llccccccc} 
& & Total & LL & LW & WL & WW & CP ratio & Z-Stat \\
\hline \multirow{2}{*}{12 months } & First vs. Second & 264 & 188 & 21 & 35 & 20 & $8.53^{* * *}$ & 5.91 \\
& Second vs. Third & 84 & 53 & 9 & 18 & 4 & 2.62 & 1.46 \\
\multirow{3}{*}{24 months } & First vs. Second & 230 & 174 & 20 & 21 & 15 & $6.53^{* * *}$ & 4.55 \\
& Second vs. Third & 81 & 60 & 4 & 14 & 3 & $11.25 * * *$ & 2.95 \\
\multirow{2}{*}{36 months } & First vs. Second & 193 & 161 & 15 & 8 & 9 & $6.44 * * *$ & 3.35 \\
& Second vs. Third & 68 & 60 & 1 & 5 & 2 & $120.00 * * *$ & 3.65 \\
\hline
\end{tabular}




\section{Table 8}

The determinants of the acquirer's survival

Panel A of Table 8 displays the survival, merger and delisting distribution of the acquiring funds t years after the merger date. Panel B and Panel C report the multinomial logit and Cox model results, respectively. We have only a few cases where an acquirer has been delisted and therefore the multinomial logit reduces to a simple logit between the survival and the merger states. The dependent variable is Survival, which equals 0 if the acquirer survives, and 1 if it is merged out. The fund characteristics are the total net assets (TNA), past performance Alpha 36 months, Age, Turnover, Fees, and Dummy family which is a dummy variable that equals 1 if this is a within-family merger and 0 if not. Frequent Dummy is a dummy variable that equals 1 if the acquisition involves a frequent acquirer and 0 if it involves an infrequent acquirer. The fund characteristics are measured at the year of the merger except for Alpha which is estimated using a window of 36 months before the merger date. Coefficients are reported in the first lines and t-stats are reported in parentheses in the second lines. ${ }^{* * *}, * *$, and $*$ indicate significance at the $0.01,0.05$, and 0.10 levels, respectively.

\section{Panel A Frequency of acquiring funds that have been merged or delisted}

\begin{tabular}{ccc}
\hline $\begin{array}{c}\text { Years after the } \\
\text { merger }\end{array}$ & Merged funds & Delisted funds \\
\hline 1 & 36 & 5 \\
2 & 70 & 1 \\
3 & 46 & 14 \\
4 & 46 & 3 \\
5 & 57 & 6 \\
$\geq 6$ & 245 & 47 \\
\hline Total & 500 & 76 \\
\hline
\end{tabular}


Panel B Logit model

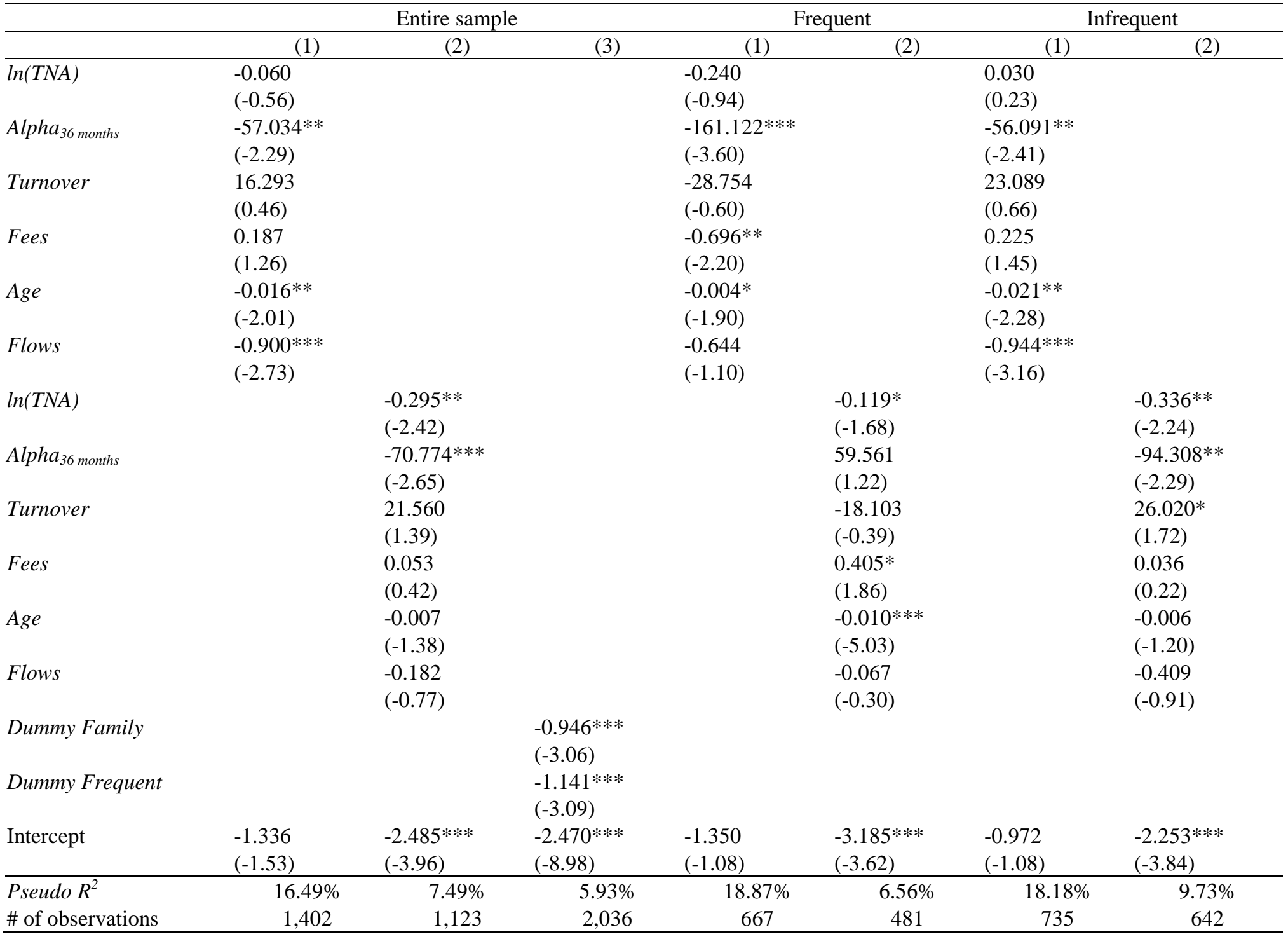




\section{Panel C Cox proportional}

\begin{tabular}{|c|c|c|c|c|c|c|c|}
\hline & \multicolumn{3}{|c|}{ Entire sample } & \multicolumn{2}{|c|}{ Frequent } & \multicolumn{2}{|c|}{ Infrequent } \\
\hline & $(1)$ & $(2)$ & (3) & $(1)$ & $(2)$ & $(1)$ & $(2)$ \\
\hline $\ln (T N A)$ & $\begin{array}{c}-0.173^{* *} \\
(-2.54)\end{array}$ & & & $\begin{array}{l}-0.169 \\
(-1.07)\end{array}$ & & $\begin{array}{c}-0.120^{*} \\
(-1.69)\end{array}$ & \\
\hline Alpha $_{36 \text { months }}$ & $\begin{array}{c}-22.159 * * * \\
(-2.76)\end{array}$ & & & $\begin{array}{c}-149.120 * * * \\
(-7.00)\end{array}$ & & $\begin{array}{c}-40.774 * * * \\
(-3.67)\end{array}$ & \\
\hline Turnover & $\begin{array}{l}1.879 \\
(0.10)\end{array}$ & & & $\begin{array}{l}7.248 \\
(0.18)\end{array}$ & & $\begin{array}{l}-9.869 \\
(-0.47)\end{array}$ & \\
\hline Fees & $\begin{array}{l}0.065 \\
(0.67)\end{array}$ & & & $\begin{array}{l}-0.393 \\
(-1.53)\end{array}$ & & $\begin{array}{l}0.125 \\
(1.23)\end{array}$ & \\
\hline Age & $\begin{array}{c}-0.005^{* * * *} \\
(-2.65)\end{array}$ & & & $\begin{array}{l}-0.002 \\
(-1.06)\end{array}$ & & $\begin{array}{c}-0.010 * * \\
(-2.29)\end{array}$ & \\
\hline Flows & $\begin{array}{c}-0.869 * * * \\
(-3.17)\end{array}$ & & & $\begin{array}{c}-1.647 * * \\
(-2.10)\end{array}$ & & $\begin{array}{c}-0.692 * * * \\
(-2.58)\end{array}$ & \\
\hline $\ln (T N A)$ & & $\begin{array}{l}-0.081 \\
(-1.30)\end{array}$ & & & $\begin{array}{l}0.090 \\
(0.85)\end{array}$ & & $\begin{array}{c}-0.180 * * \\
(-2.29)\end{array}$ \\
\hline Alpha $_{36 \text { months }}$ & & $\begin{array}{c}-53.188^{* * * *} \\
(-3.45)\end{array}$ & & & $\begin{array}{c}-59.114 * * \\
(-2.42)\end{array}$ & & $\begin{array}{c}-37.615^{*} \\
(-1.80)\end{array}$ \\
\hline Turnover & & $\begin{array}{c}-10.666 \\
(-0.69)\end{array}$ & & & $\begin{array}{c}-12.151 \\
(-0.48)\end{array}$ & & $\begin{array}{c}-15.455 \\
(-0.81)\end{array}$ \\
\hline Fees & & $\begin{array}{c}0.219 * * \\
(2.22)\end{array}$ & & & $\begin{array}{c}0.474^{* * *} \\
\quad(3.83)\end{array}$ & & $\begin{array}{l}0.018 \\
(0.13)\end{array}$ \\
\hline Age & & $\begin{array}{l}0.001 \\
(0.65)\end{array}$ & & & $\begin{array}{l}0.001 \\
(0.84)\end{array}$ & & $\begin{array}{l}0.000 \\
(0.13)\end{array}$ \\
\hline Flows & & $\begin{array}{l}-0.199 \\
(-1.33)\end{array}$ & & & $\begin{array}{l}-0.053 \\
(-0.39)\end{array}$ & & $\begin{array}{l}-0.346 \\
(-1.51)\end{array}$ \\
\hline Dummy Family & & & $\begin{array}{c}-0.733^{* * *} \\
(-6.11)\end{array}$ & & & & \\
\hline Dummy Frequent & & & $\begin{array}{c}-0.399 * * * \\
(-3.31)\end{array}$ & & & & \\
\hline \# of observations & 1,336 & 1,065 & 1,871 & 646 & 470 & 690 & 595 \\
\hline
\end{tabular}

